\title{
Solubility, Stability, and Avidity of Recombinant Antibody Fragments Expressed in Microorganisms
}

\author{
Tae Hyun Kang ${ }^{1}$ and Baik Lin Seong ${ }^{2,3 *}$ \\ 'Biopharmaceutical Chemistry Major, School of Applied Chemistry, Kookmin University, Seoul, South Korea, ${ }^{2}$ Department \\ of Biotechnology, College of Life Science and Biotechnology, Yonsei University, Seoul, South Korea, ${ }^{3}$ Vaccine Innovative \\ Technology ALliance (VITAL)-Korea, Yonsei University, Seoul, South Korea
}

\section{OPEN ACCESS}

Edited by:

Georgios Skretas, National Hellenic Research

Foundation, Greece

Reviewed by: Xin $\mathrm{Ge}$,

University of California, Riverside, United States Pietro Sormanni, University of Cambridge, United Kingdom

*Correspondence:

Baik Lin Seong

blseong@yonsei.ac.kr

Specialty section:

This article was submitted to Microbial Physiology and Metabolism,

a section of the journal

Frontiers in Microbiology

Received: 15 April 2020

Accepted: 22 July 2020

Published: 25 September 2020

Citation:

Kang TH and Seong BL (2020)

Solubility, Stability, and Avidity of Recombinant Antibody Fragments

Expressed in Microorganisms.

Front. Microbiol. 11:1927.

doi: 10.3389/fmicb.2020.01927
Solubility of recombinant proteins (i.e., the extent of soluble versus insoluble expression in heterogeneous hosts) is the first checkpoint criterion for determining recombinant protein quality. However, even soluble proteins often fail to represent functional activity because of the involvement of non-functional, misfolded, soluble aggregates, which compromise recombinant protein quality. Therefore, screening of solubility and folding competence is crucial for improving the quality of recombinant proteins, especially for therapeutic applications. The issue is often highlighted especially in bacterial recombinant hosts, since bacterial cytoplasm does not provide an optimal environment for the folding of target proteins of mammalian origin. Antibody fragments, such as single-chain variable fragment (scFv), single-chain antibody (scAb), and fragment antigen binding (Fab), have been utilized for numerous applications such as diagnostics, research reagents, or therapeutics. Antibody fragments can be efficiently expressed in microorganisms so that they offer several advantages for diagnostic applications such as low cost and high yield. However, scFv and scAb fragments have generally lower stability to thermal stress than full-length antibodies, necessitating a judicious combination of designer antibodies, and bacterial hosts harnessed with robust chaperone function. In this review, we discuss efforts on not only the production of antibodies or antibody fragments in microorganisms but also scFv stabilization via (i) directed evolution of variants with increased stability using display systems, (ii) stabilization of the interface between variable regions of heavy $\left(V_{H}\right)$ and light $\left(V_{L}\right)$ chains through the introduction of a non-native covalent bond between the two chains, (iii) rational engineering of $V_{H}-V_{L}$ pair, based on the structure, and (iv) computational approaches. We also review recent advances in stability design, increase in avidity by multimerization, and maintaining the functional competence of chimeric proteins prompted by various types of chaperones.

Keywords: antibody fragments, solubility, stability, bacterial expression, scFv

\section{INTRODUCTION}

Antibodies are widely used for medical applications such as disease diagnosis and therapy (Grilo and Mantalaris, 2019). Valuable pharmaceutical properties of antibodies such as high affinity to their target molecules have led to them becoming constituted as key materials not only in antibody-based biosensors, which offer the promise of in-depth target detection capacity 
(Holliger and Hudson, 2005; Saerens et al., 2008; Conroy et al., 2009) but also in antibody-based proteomics, which provides insights into cancer disease states via cancer biomarker discovery (Brennan et al., 2010). In addition to the intrinsic property, industrial applications require high productivity and long shelflife from thermal stress, organic solvents, and other stresses than physiological conditions. However, production of full-length antibodies cost extremely high, as they are typically expressed in mammalian cell lines such as Chinese hamster ovary ( $\mathrm{CHO}$ ) or NS0 murine myeloma cell lines (de la Cruz Edmonds et al., 2006; Huang et al., 2007; Liu et al., 2008; Grilo and Mantalaris, 2019) due to N-glycan heterogeneity among different species (Jefferis, 2009) and also the complex disulfide bond pattern; hence, the biopharmaceutics industry has devoted immense resources on its production processes (Chartrain and Chu, 2008). Instead, the single-chain variable fragment ( $\mathrm{scFv}$, Figure 1), a rational polypeptide design, consisting only of variable regions from heavy $\left(\mathrm{V}_{H}\right)$ and light $\left(\mathrm{V}_{L}\right)$ chains, joined together by a linker, not only maintains antigen binding capacity (Humphreys, 2003; Andersen and Reilly, 2004) but also can easily be produced in prokaryotes, such as Escherichia coli (E. coli) or Brevibacillus choshinensis (B. chosinensis) (Hu et al., 2017), along with high yield, which keeps the cost of production low (Power and Hudson, 2000; Terpe, 2006; Rosano and Ceccarelli, 2014; Gupta and Shukla, 2017). Despite the advantages of scFvs, they have a few drawbacks that limit their therapeutic potential, such as (i) deteriorated stability because of their propensity to readily aggregate under thermal stress (Jager and Pluckthun, 1999a; Demarest and Glaser, 2008); (ii) a short serum half-life of $<1$ day compared to 3 weeks for full-length immunoglobulin G (IgG)1, IgG2, and IgG4 antibodies (Kang and Jung, 2020); and (iii) reduced affinity compared to the full-length antibody counterpart. Therefore, scFv format is suitable for limited cases, such as macular degeneration or blood-related diseases (Table 1).

Immunoglobulin $\mathrm{G}$, the most abundant monoclonal antibody (mAb) isotype in serum is composed of two antigen binding fragments (Fab) and one homodimeric fragment crystallizable (Fc) domain that contribute to the overall stability of the molecule (Figure 1; Kang and Jung, 2019; Saunders, 2019). Since Fab of an IgG becomes more sensitive to the heat denaturation when Fc region is removed (Tischenko et al., 1982; Vermeer and Norde, 2000; Ionescu et al., 2008), researchers have tried to engineer Fab to stabilize the interactions between constant heavy $1\left(\mathrm{C}_{H} 1\right)$ and constant light $\left(\mathrm{C}_{L}\right)$ chains in order to obviate the need for using mammalian host cells for the expression of full-length antibodies because of $N$-glycan on the Fc region. This requires immense resources such as expensive media, facilities to maintain germfree conditions, and time. However, limited successes have been made (Demarest et al., 2006; Teerinen et al., 2006). Further elimination of $\mathrm{C}_{H} 1-\mathrm{C}_{L}$ pair in Fab, resulting in fragment variable (Fv), significantly discounts thermodynamic stability (Webber et al., 1995; Jager and Pluckthun, 1999b). This is presumably due to the unnatural exposure of the lower $\mathrm{V}_{L}$ and $\mathrm{V}_{H}$ regions, flanking $\mathrm{C}_{H} 1$ and $\mathrm{C}_{L}$, where hydrophobic interaction used to contribute to the stability as a whole as well as the absence of the contribution of $\mathrm{C}_{H} 1$, which controls the assembly of heavy and light chains of the whole IgG molecule (Feige et al., 2009).
The only light-heavy intermolecular disulfide bond in native IgG antibodies on the residues Cys220 in $\mathrm{C}_{H} 1$ and Cys214 in $\mathrm{C}_{L}$ of Fab region (Figure 2 in canakinumab; PDB ID of 5BVJ) contributes to the thermodynamic stability of the whole Fab fragment. In addition, intramolecular disulfide bonds in both the $\mathrm{V}_{H}$ and $\mathrm{V}_{L}$ regions (Figure 2) is critical in the thermodynamic stability because elimination of them significantly enhanced the propensity of scFv aggregation (Montoliu-Gaya et al., 2017). In this article we review efforts on increasing expression yield as well as protein stability of antibody fragment and recent diverse designs of antibody fragments.

\section{PRODUCTION OF ANTIBODY OR ANTIBODY FRAGMENTS IN BACTERIA}

To reduce the cost of production of antibodies, researchers in both academia and industry put enormous efforts on elevating expression yield of IgG antibody or its fragment by (i) engineering expression plasmids, i.e., rhamnose-inducible expression system (Petrus et al., 2019) or comprehensive optimization via high-throughput screening (Makino et al., 2011), (ii) engineering global sigma factor RhoD, which regulates more than 1,000 gene expressions (McKenna et al., 2019), and (iii) devising bacterial strains capable of forming disulfide bonds in cytoplasm such as CyDisCo (Gaciarz and Ruddock, 2017) or SHuffle (Lobstein et al., 2012; Robinson et al., 2015; Yusakul et al., 2017). Despite the advantages, drawbacks limiting its potential are (i) the low stability of scFvs, known for their propensity to readily aggregate under thermal stress (Jager and Pluckthun, 1999a; Demarest and Glaser, 2008), (ii) absence of glycosylation machinery, (iii) lack of efficient secretory mechanism as compared to yeast or animal cells, functionally limited protein trafficking machinery from the cytoplasm to the periplasmic space or to the outside of the cells, and (iv) overproduction of acetic acid byproduct during fermentation (Holms, 1986; Wong et al., 2008).

\section{ENGINEERING INTRINSIC STABILITY OF SCFVS: DIRECTED EVOLUTION, RATIONAL DESIGN, AND COMPUTATIONAL APPROACHES}

Antibody fragments can be expressed in several compartments in E. coli: mostly as inclusion bodies in the cytoplasm, or as soluble forms displayed on (i) the inner membrane, (ii) in the periplasmic space, (iii) on the outer membrane, and/or (iv) outside the bacterium, facilitated by various signal sequences, such as outer membrane protein A (OmpA), pectate lyase B (PelB), or new lipoprotein A (NlpA) (Tseng et al., 2009; Frenzel et al., 2013; Khodabakhsh et al., 2013; Levy et al., 2013; DePalma, 2014; Mizukami et al., 2018). To overcome the drawbacks of scFvs, which comprise only $\mathrm{V}_{H}$ and $\mathrm{V}_{L}$ antigen-binding domains, to reduce the protein size in order to increase protein production but maintain high target molecule affinity, researchers have engineered 

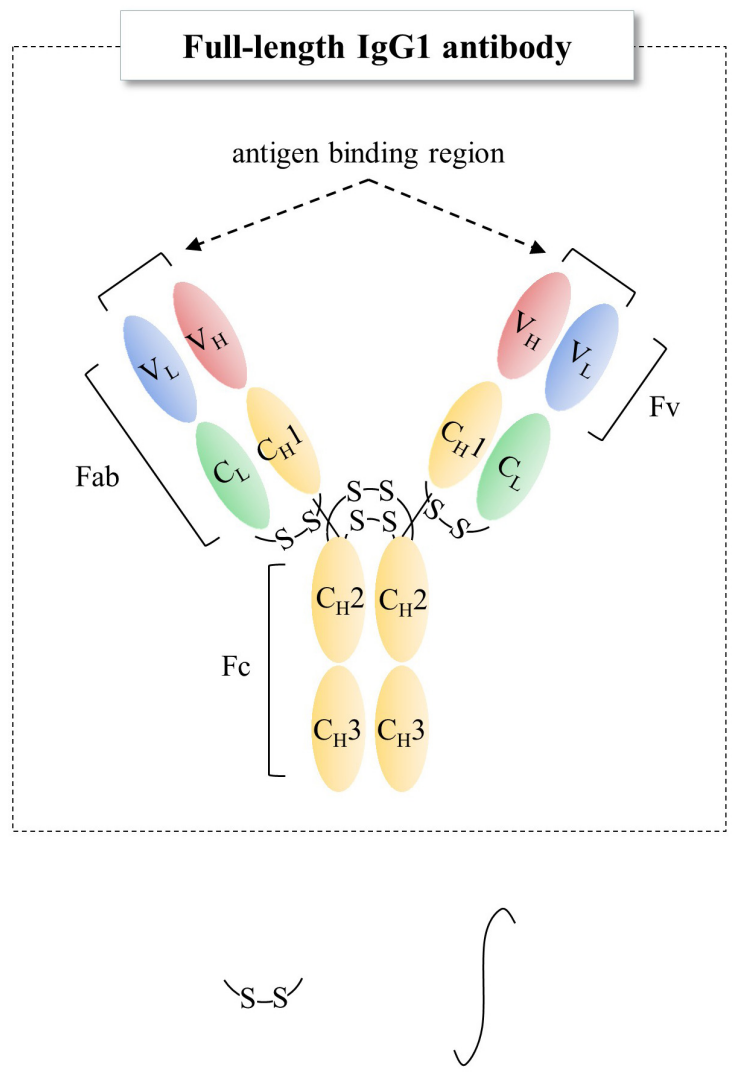

intermolecular disulfide bond

$\left(\mathrm{G}_{4} \mathrm{~S}\right)_{3}$ linker
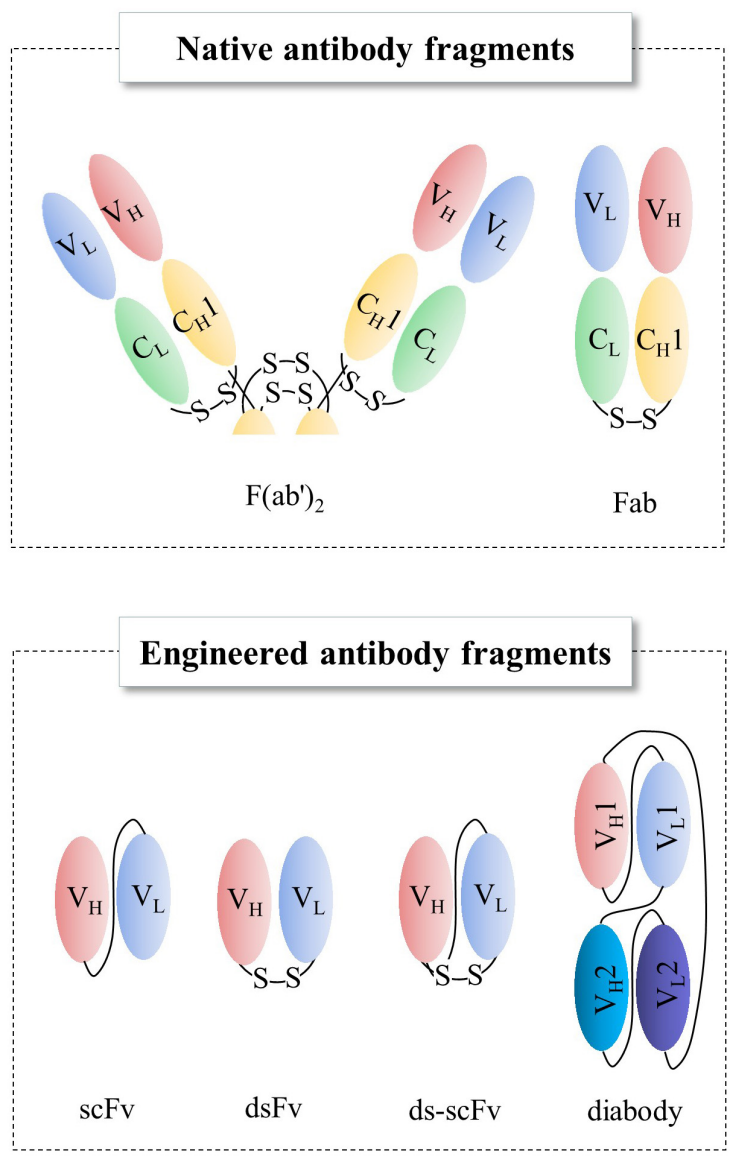

FIGURE 1 | Schematic representations of full-length IgG1 antibody and antibody fragments. Fab, fragment antigen binding; Fv, fragment variable; Fc, fragment crystallizable; scFv, single-chain Fv; dsFv, disulfide-stabilized Fv.

scFvs with resistance to aggregation and enhanced intrinsic stability of antibody fragments. Table 2 summarizes the engineering efforts.

\section{Directed Evolution}

Greg Winter et al., utilized phage display directed evolution methodology to isolate $\mathrm{V}_{H}$ variants that are more resistant to heat denaturation (Jespers et al., 2004). They further engineered $\mathrm{V}_{H}$ and identified a key residue, $\operatorname{Arg} 28$ in $\mathrm{V}_{H}$ that renders resistance to heat and acid aggregation (Famm et al., 2008). Daniel Christ's group at the Garvan Institute of Medical Research selected critical residues for antigen binding in both $\mathrm{V}_{H}$ and $\mathrm{V}_{L}$ and constructed a phage library introducing aspartate or glutamate in those residues to screen for heat resistance. The isolated variants resulted in not only enhanced biophysical property but also structural conservation (Dudgeon et al., 2012). Dane Wittrup's group at MIT devised a yeast surface display system to isolate $\mathrm{scFv}$ variants with high affinity to antigen and increased stability by constructing yeast mutant libraries, expressing $\mathrm{scFv}$ on the cell surface, followed by successive rounds of flow cytometry sorting (Graff et al., 2004; Chao et al., 2006). Brian Miller et al., at Biogen Idec,
Inc. used sequence- and structure-based analyses to devise a high-throughput screening methodology that measure scFv extracellularly expressed by E. coli. This screening methodology resulted in enhanced melting temperature (Tm) by $14^{\circ} \mathrm{C}$ and additional Tm improvement by $12^{\circ} \mathrm{C}$ through combination of the resulting variants (Miller et al., 2010).

\section{Rational Design}

Unlike the presence of intermolecular $\mathrm{C}_{H} 1-\mathrm{C}_{L}$ disulfide bond, there is not one in the native $\mathrm{V}_{H}-\mathrm{V}_{L}$ (Figures 1, 2). Instead of placing a linker between $\mathrm{V}_{H}$ and $\mathrm{V}_{L}(\mathrm{scFv}$ in Figure 1) creating non-native disulfide bond between $\mathrm{V}_{H}$ and $\mathrm{V}_{L}$ via substituting amino acid residues in both framework 2 (FR2) in $\mathrm{V}_{H}$ and FR4 in $\mathrm{V}_{L}$ (dsFv; disulfide-stabilized Fv in Figure 1) led to indistinguishable specificity to antigen and similar cytotoxic activity when fused with exotoxin but exhibited superior protein stability at $37^{\circ} \mathrm{C}$, compared to $\mathrm{scFv}$ counterpart (Brinkmann et al., 1993). Similarly, substitution of Val84 in $\mathrm{V}_{H}$ to aspartic acid led to not only improved periplasmic production by 25 -fold but also decreased the rate of thermally induced aggregation reaction (Nieba et al., 1997). In another study, introduction of Cys44 in $\mathrm{V}_{H}$ and Cys100 in $\mathrm{V}_{L}$ in 
TABLE 1 | FDA approved therapeutic antibody fragments.

\begin{tabular}{|c|c|c|c|c|c|c|c|}
\hline Name $^{1}$ & Brand name $^{2}$ & Company $^{3}$ & Target & Format & Indication ${ }^{4}$ & $\begin{array}{c}\text { Year } \\
\text { approved }^{5}\end{array}$ & Host $^{6}$ \\
\hline Abciximab & Reopro & $\begin{array}{l}\text { Janssen Biotech, } \\
\text { Inc. }\end{array}$ & GPIIb/IIla & $\begin{array}{l}\text { Chimeric lgG1 } \\
\text { Fab }\end{array}$ & $\begin{array}{l}\text { Prevention of blood clots in } \\
\text { angioplasty }\end{array}$ & 1994 & Mammalian \\
\hline Ranibizumab & Lucentis & Genentech, Inc. & VEGF & $\begin{array}{l}\text { Humanized } \\
\text { lgG1 Fab }\end{array}$ & Macular degeneration & 2006 & E. coli \\
\hline $\begin{array}{l}\text { Certolizumab } \\
\text { pegol }\end{array}$ & Cimzia & UCB, Inc. & TNF & $\begin{array}{l}\text { Humanized } \\
\text { Fab, pegylated }\end{array}$ & Crohn disease & 2008 & E. coli \\
\hline Blinatumomab & Blincyto & Amgen Inc. & CD19, CD3 & $\begin{array}{c}\text { Murine } \\
\text { bispecific } \\
\text { tandem scFv }\end{array}$ & Acute lymphoblastic leukemia & 2014 & E. coli \\
\hline Idarucizumab & Praxbind & $\begin{array}{c}\text { Boehringer } \\
\text { Ingelheim } \\
\text { Pharmaceuticals, } \\
\text { Inc. }\end{array}$ & Dabigatran & Humanized Fab & $\begin{array}{l}\text { Reversal of dabigatran-induced } \\
\text { anticoagulation }\end{array}$ & 2015 & $\mathrm{CHO}^{7}$ \\
\hline $\begin{array}{l}\text { Moxetumomab } \\
\text { pasudotox }\end{array}$ & Lumoxiti & $\begin{array}{c}\text { AstraZeneca } \\
\text { Pharmaceuticals LP }\end{array}$ & CD22 & $\begin{array}{l}\text { Murine IgG1 } \\
\text { dsFv } \\
\text { immunotoxin }\end{array}$ & Hairy cell leukemia & 2018 & E. coli \\
\hline Caplacizumab & Cablivi & Ablynx N.V. & $\begin{array}{l}\text { von Willebrand } \\
\text { factor }\end{array}$ & $\begin{array}{l}\text { Humanized } \\
\text { Nanobody }\end{array}$ & $\begin{array}{l}\text { Acquired thrombotic } \\
\text { thrombocytopenic purpura }\end{array}$ & 2019 & E. coli \\
\hline Brolucizumab & Beovu & $\begin{array}{c}\text { Novartis } \\
\text { Pharmaceuticals } \\
\text { Corporation }\end{array}$ & VEGF-A & $\begin{array}{l}\text { Humanized } \\
\text { scFv }\end{array}$ & $\begin{array}{c}\text { Neovascular } \\
\text { age-related macular degeneration }\end{array}$ & 2019 & E. coli \\
\hline
\end{tabular}

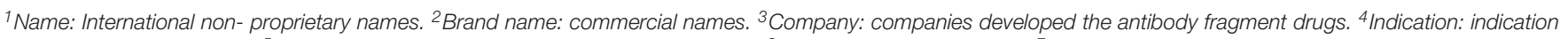

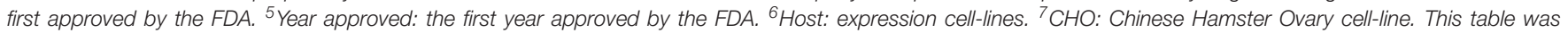
classified using data from "The Antibody Society (2020)" (Antibody Society, 2020).

anti-aflatoxin $\mathrm{B}(1) \mathrm{scFv}$ resulted in improved stability and resistance to protein aggregation (Zhao et al., 2010). Introduction of the disulfide bond to anti-FGF2 diabody (ds-diabody, see section "multimerization" for diabody) also improved biological activity (Cai et al., 2016). This is presumably due to its lower propensity to the open state of $\mathrm{V}_{H}-\mathrm{V}_{L}$ pair, in contrast to the presence of both assembled and disassembled state in case of scFv where $\mathrm{V}_{H}$ and $\mathrm{V}_{L}$ domains are simply connected by a $\mathrm{G}_{4} \mathrm{~S}$ linker. These results indicate that bridging $\mathrm{V}_{H}$ and $\mathrm{V}_{L}$ by establishing intermolecular disulfide bond formation via cysteine residue incorporation can be a decent strategy for Fv stabilization (Trivedi et al., 2009). Another recent approach incorporating closed state of $\mathrm{V}_{H^{-}} \mathrm{V}_{L}$ pair is a cyclization of $\mathrm{scFv}$ using an enzyme sortase $\mathrm{A}$, which ligate the pair, leading to cyclic scFv: this methodology markedly suppressed aggregation tendency without affecting affinity to antigen (Yamauchi et al., 2019).

Alexey Lugovskoy et al., at Merrimack Pharmaceuticals, Inc. showed that both essential and non-essential tyrosine residues for antigen binding in either CDR or FR can improve the biophysical property of scFv (Zhang et al., 2015). An-Suei Yang et al., at the National Defense Medical Center, Taipei, elucidated the nature of intra- and inter-hydrophobic domains of scFv: the former is flexible and indirectly affects antigen binding, as opposed to the latter affecting antigen binding directly (Hsu et al., 2014). Robin Curtis's group at the University of Manchester investigated the aggregation propensity of argininerich $s c F v$ under denaturing condition: substitution of arginine residues in $\mathrm{scFv}$ with lysine significantly reduced aggregation (Austerberry et al., 2019). This diverse knowledge of protein nature in scFv may assist engineers with consensus-based design of antibody fragment for generating stabilizing mutations to pre-existing scFvs (Steipe, 2004) or bispecific antibody fragments (Jordan et al., 2009).

\section{Computational Approaches}

Andreas Plückthun's group at University of Zurich designed a stabilized $s c F v$ from human $\mathrm{V}_{H}$ germline sequences by analyzing hydrophobic core, pairing of hydrogen bonds, clusters of charge, and packing of $\beta$-sheets, leading to reduction of $\Delta \mathrm{G}=20.9 \mathrm{~kJ} / \mathrm{mol}$ as well as improvement of scFv expression yield by 4-fold (Ewert et al., 2003). Furthermore, they could stabilize $s c F v$ by CDR grafting to more stable framework, using a structure-based analysis (Ewert et al., 2004).

Computational web servers, such as Prediction of Immunoglobulin Structure (PIGS) (Marcatili et al., 2008) or Web Antibody Modeling (WAM) (Whitelegg and Rees, 2000), made computational modeling of antibody variable regions possible. Importantly, recent advances in structural knowledge and computational protein modeling such as RosettaDesign accelerated antibody design toward improved antigen affinity as well as physicochemical properties (Borgo and Havranek, 2012; Buck et al., 2012). The homology modeling provides with guidance on not only prediction on the conformations of CDR loops but also $\mathrm{V}_{H^{-}}-\mathrm{V}_{L}$ orientations via energy calculations such as antibody-antigen docking, comparing with known crystal structures (Kuroda et al., 2012). For example, a computational homology modeling significantly improved resistance of scFvs to heat inactivation 


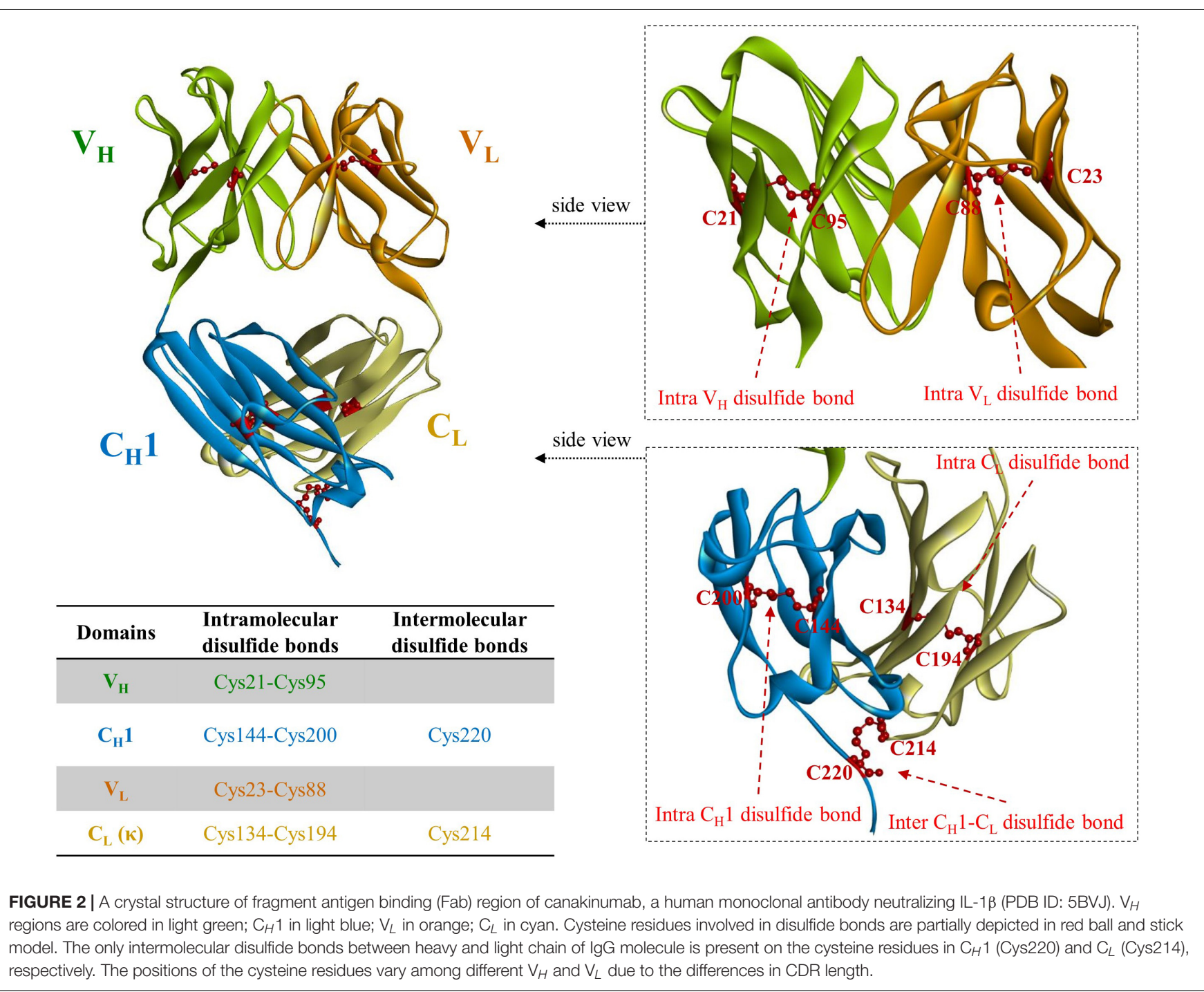

by supercharging the protein through energy calculations (Lawrence et al., 2007; Miklos et al., 2012). In addition, combinatorial engineering approach, including CDR grafting onto stable frameworks, $\mathrm{V}_{H}-\mathrm{V}_{L}$ interface stabilization, and in vitro somatic hypermutation significantly increased thermal stability of full-length antibody by $10^{\circ} \mathrm{C}$, compared to the native IgG1 antibody (McConnell et al., 2013, 2014).

Recent advances in computational methodologies for both antibody sequencing and backbones (Goldenzweig and Fleishman, 2018) and for multistage processing of antibody engineering, capitalizing on computational design and experimental validation cycles (Baran et al., 2017), have enabled successful de novo antibody engineering (Chevalier et al., 2017), such as anti-influenza antibodies (Strauch et al., 2017; Sevy et al., 2019). Of note, Georgiou and Ellington at the University of Texas at Austin used the Rosetta modeling program (Sircar et al., 2009; AdolfBryfogle et al., 2018) to predict amino acid substitutions for anti-HA33 scFv stabilization and confirmed a melting temperature increase of $4.5^{\circ} \mathrm{C}$ by antigen-binding enzyme-linked immunosorbent assay (ELISA) after thermal stress for $2 \mathrm{~h}$ at $70^{\circ} \mathrm{C}$ (Lee et al., 2019).

\section{A FUSION PARTNER}

Tagging of anti-FGFR3 scFv with a solubilizing partner small ubiquitin-related modifier (Sumo), followed by removal of the Sumo protein using Sumo protease, enabled over 95\% purity with the yield of $4 \mathrm{mg} / \mathrm{L}$ bacterial culture. The resulting antiFGFR3 scFv has exhibited complete biological activity (Liu et al., 2015). Another example is an "Fv-clasp," where scFv was fused with anti-parallel coiled coil structure, SRAH domain of human Mst1 with scFv. In addition, introduction of disulfide bond to the Fv greatly enhanced thermal stability and tendency of crystallization. This is presumably due to the shielding of hydrophobic residues exposed in Fv, according to the X-ray crystallography (Arimori et al., 2017). Alternatively, approaches 
TABLE 2 | Summary of stability and avidity engineering of scFvs in bacteria.

\begin{tabular}{|c|c|c|c|c|}
\hline Classification & Group & Institute & Methodology & References \\
\hline \multirow[t]{4}{*}{ Directed evolution } & Gregory Winter & University of Cambridge & Phage display & Jespers et al., 2004 \\
\hline & Daniel Christ & $\begin{array}{c}\text { Garvan Institute of Medical } \\
\text { Research }\end{array}$ & Phage display & Dudgeon et al., 2012 \\
\hline & Dane Wittrup & MIT & Yeast display & Graff et al., 2004; Chao et al., 2006 \\
\hline & Scott Glaser & Biogen Idec & Bacterial screening & Miller et al., 2010 \\
\hline \multirow[t]{10}{*}{ Rational design } & Ira Pastan & $\mathrm{NIH}$ & Non-native disulfide bond & Brinkmann et al., 1993 \\
\hline & Andreas Plückthun & University of Zurich & Disrupting the hydrophobic patches & Nieba et al., 1997 \\
\hline & Wei Chen & Jiangnan University & Non-native disulfide bond & Zhao et al., 2010 \\
\hline & Ning Deng & Jinan University & Non-native disulfide bond & Cai et al., 2016 \\
\hline & Hiroshi Morioka & Kumamoto University & Cyclization of scFv & Yamauchi et al., 2019 \\
\hline & Alexey Lugovskoy & Merrimack Pharmaceuticals & Tyrosine substitution & Zhang et al., 2015 \\
\hline & An-Suei Yang & $\begin{array}{c}\text { National Defense Medical Center in } \\
\text { Taipei }\end{array}$ & Hydrophobic domains & Hsu et al., 2014 \\
\hline & Robin Curtis & University of Manchester & Substitution of Arginine & Austerberry et al., 2019 \\
\hline & Boris Steipe & University of Toronto & Consensus-based & Steipe, 2004 \\
\hline & Alexey Lugovskoy & Biogen Idec & Consensus-based & Jordan et al., 2009 \\
\hline \multirow[t]{5}{*}{ Computation } & Andreas Plückthun & University of Zurich & Structure-based & Ewert et al., 2003, 2004 \\
\hline & David R. Liu & Harvard University & Supercharging & Lawrence et al., 2007 \\
\hline & Andrew Ellington & University of Texas at Austin & Supercharging & Miklos et al., 2012 \\
\hline & Peter Bowers & AnaptysBio & Integrative approach & $\begin{array}{l}\text { McConnell et al., 2013; McConnell } \\
\text { et al., } 2014\end{array}$ \\
\hline & $\begin{array}{c}\text { George Georgiou and Andrew } \\
\text { Ellington }\end{array}$ & University of Texas at Austin & Rosetta modeling & Lee et al., 2019 \\
\hline \multirow[t]{2}{*}{ Fusion partner } & Yechen Xiao & Jilin University & SUMO & Liu et al., 2015 \\
\hline & Junichi Takagi & Osaka University & Fv-clasp & Arimori et al., 2017 \\
\hline Chaperone coexpression & Shihua Wang & $\begin{array}{c}\text { Fujian Agriculture and Forestry } \\
\text { University }\end{array}$ & Skp & Wang et al., 2013 \\
\hline \multirow[t]{2}{*}{ Multimerization } & Sergey Kipriyanov & Affimed Therapeutics AG & Diabody: bispecific & Le Gall et al., 2004 \\
\hline & C Ronald Geyer & University of Saskatchewan & SpyCatcher: trispecific & Alam et al., 2018 \\
\hline
\end{tabular}

based on the chaperone function of RNAs could also be considered (Choi et al., 2008). Fusion with an RNA-interaction domain (RID) greatly enhances the solubility (i.e., the ratio of soluble versus insoluble expression in heterogeneous hosts) and the overall yield of soluble proteins, harnessed with unique properties of RNAs as chaperone (chaperna; chaperone + RNA) (Kim et al., 2018; Yang et al., 2018), although this approach has not yet been documented for recombinant antibody fragments.

\section{ENGINEERING THE HOST CELL: CHAPERONE COEXPRESSION OR GENOME-LEVEL SCREENING}

The folding of nascent polypeptides is often assisted by molecular chaperones (Hendrick and Hartl, 1995; Bukau and Horwich, 1998; Hartl and Hayer-Hartl, 2002), although their utility in recombinant expression has been documented only in limited cases (Structural Genomics Consortium et al., 2008). The stability problem associated with $\mathrm{V}_{H}-\mathrm{V}_{L}$ pair in the scFv molecule can be circumvented through assistance with the chaperone of a pairing vehicle. Coexpression of the chaperone Skp enhanced binding activity of anti-TLH scFv by 3-4 fold, relative to the native counterpart, expressed in E. coli (Wang et al., 2013).

\section{MULTIMERIZATION}

Diabodies not only render bivalency but also enhance stability of Fv by linker design (Le Gall et al., 2004). Introducing covalent bonds between $\mathrm{V}_{H} 1$ and $\mathrm{V}_{L} 2$ as well as $\mathrm{V}_{H} 2$ and $\mathrm{V}_{L} 1$ enables bispecific binding capacity of the two distinct $s c F v$ in one molecule (diabody in Figure 1). One example in clinic is blinatumomab (BLINCYTO, ${ }^{\circledR}$ 2014), a bispecific scFv for CD19 and CD3 (Table 1), which functions as a T lymphocyte engager to cancerous B lymphocytes for the treatment of acute lymphoblastc leukemia (Holliger et al., 1993; Mack et al., 1995; Suresh et al., 2014; Wu et al., 2015). In addition, constructing antiHER3 trivalent scFv using SpyCatcher ligase system enhanced affinity by 12 -fold as compared to a monomeric anti-HER3 counterpart (Alam et al., 2018). Another general approach of antibody fragments is the utilization of targeting ligands on nanoparticles in nanomedicine (Richards et al., 2017). Several antibody fragment-based nanoparticles are under clinical trials, including Erbitux-EDVS ${ }_{\mathrm{pac}}$, which is a bacteria-derived mini-cell nanoparticle targeting EGFR currently under clinical phase II (Richards et al., 2017). Multimerization of scFvs as nanoparticles, using self-assembling scaffolds via chaperna approach (Kim et al., 2018; Yang et al., 2018) holds promise for further enhancing the avidity and thermostability of recombinant antibody fragments. 


\section{CONCLUSION}

Up to March 2020, the US Food and Drug Administration (FDA) approved eight antibody fragments as drugs, six of which are produced from E. coli (75\%, Table 1). The six therapeutic antibody fragments, produced by bacteria include ranibizumab (LUCENTIS ${ }^{\circledR}, 2006$ ), certolizumab pegol $\left(\right.$ CIMZIA $^{\circledR}$, 2008), blinatumomab (BLINCYTO $^{\circledR}$, 2014), moxetumomab pasudotox (Kreitman and Pastan, 2011; LUMOXITI $^{\text {TM }}$, 2018), caplacizumab (CABLIVI $^{\circledR}$, 2019), and brolucizumab (BEOVU $\left.{ }^{\circledR}, 2019\right)$, while those produced by mammalian hosts include abciximab (ReoPro $\left.{ }^{\circledR}, 1994\right)$ and idarucizumab (PRAXBIND $\left.{ }^{\circledR}, 2015\right)$, according to the data from "The Antibody Society" (Antibody Society, 2020).

Microorganisms are favorable expression hosts for antibody fragments, such as scFvs or Fab, in therapeutic applications (Table 1), because of the low production cost and lack of a carbohydrate chain. However, despite these advantages, scFvs expressed in bacteria have neither comparable stability relative to native full-length antibodies nor a comparable production yield of $\sim 1 \mathrm{~g} / \mathrm{L}$ in bioreactors (Petrus et al., 2019) relative to mammalian hosts, that is, $>10 \mathrm{~g} / \mathrm{L}$ in $\mathrm{CHO}$ cells (Kunert and Reinhart, 2016). Therefore, scientists and engineers in both academia and industry put extensive efforts on increasing production yield as well as protein stability of $s c F v$ expressed in bacteria. To obtain improved yield various bacterial expression systems have been developed in terms of vector systems or engineered strains with engineered chaperone molecules.

\section{REFERENCES}

Adolf-Bryfogle, J., Kalyuzhniy, O., Kubitz, M., Weitzner, B. D., Hu, X., Adachi, Y., et al. (2018). RosettaAntibodyDesign (RAbD): a general framework for computational antibody design. PLoS Comput. Biol. 14:e1006112. doi: 10.1371/ journal.pcbi.1006112

Alam, M. K., Brabant, M., Viswas, R. S., Barreto, K., Fonge, H., and Ronald Geyer, C. (2018). A novel synthetic trivalent single chain variable fragment (tri-scFv) construction platform based on the SpyTag/SpyCatcher protein ligase system. BMC Biotechnol. 18:55. doi: 10.1186/s12896-018-0466-6

Andersen, D. C., and Reilly, D. E. (2004). Production technologies for monoclonal antibodies and their fragments. Curr. Opin. Biotechnol. 15, 456-462. doi: 10. 1016/j.copbio.2004.08.002

Antibody Society (2020). Available online at: https://www.antibodysociety.org/ resources/approved-antibodies/ (accessed March 10, 2020).

Arimori, T., Kitago, Y., Umitsu, M., Fujii, Y., Asaki, R., Tamura-Kawakami, K., et al. (2017). Fv-clasp: an artificially designed small antibody fragment with improved production compatibility, stability, and crystallizability. Structure 25, 1611-1622. doi: 10.1016/j.str.2017.08.011

Austerberry, J. I., Thistlethwaite, A., Fisher, K., Golovanov, A. P., Pluen, A., Esfandiary, R., et al. (2019). Arginine to Lysine mutations increase the aggregation stability of a single-chain variable fragment through unfolded-state interactions. Biochemistry 58, 3413-3421. doi: 10.1021/acs.biochem.9b00367

Baran, D., Pszolla, M. G., Lapidoth, G. D., Norn, C., Dym, O., Unger, T., et al. (2017). Principles for computational design of binding antibodies. Proc. Natl. Acad. Sci. U.S.A. 114, 10900-10905. doi: 10.1073/pnas.170717 1114

BEOVU $^{\circledR}$ (2019). Prescribing Information Approved by the U.S. Food and Drug Administration. (U.S. License Number: 1244). East Hanover, NJ: Novartis Pharmaceuticals Corporation.
The low intrinsic solubility and stability of native $\mathrm{scFv}$ protein with a relatively shorter shelf-life is a bottleneck for industrial application. To overcome the disadvantages there have been enormous research attempts on stability design via site-directed mutagenesis, generation of non-natural covalent bonds between the heavy and light variable chains, rational design, and recently computer-based engineering or chimeric approaches. Engineering of $\mathrm{scFv}$ with respect to increasing the stability lowers both the kinetic complexity in folding process and subsequently the propensity to aggregate into non-functional form. Folding into soluble, functional form with the desired level of avidity is often aided by exploiting the chaperone function of naturally existing molecular chaperones or artificial solubilizing tags. Besides thermodynamic aspects on overall stability, due consideration should be given to the kinetic aspects in de novo folding pathway for designer antibody fragments toward improved solubility, thermal stability, and productivity.

\section{AUTHOR CONTRIBUTIONS}

TK and BS designed and wrote the manuscript. Both authors agreed to be accountable for the content of the work.

\section{FUNDING}

This work was supported by grants from the Korean government (NRF-2020R1F1A1072124, NRF-2018M3A9H4079358, and HI20C0144).

BLINCYTO $^{\circledR}$ (2014). Prescribing Information Approved by the U.S. Food and Drug Administration. (U.S. License No. 1080). Thousand Oaks, CA: Amgen Inc.

Borgo, B., and Havranek, J. J. (2012). Automated selection of stabilizing mutations in designed and natural proteins. Proc. Natl. Acad. Sci. U.S.A. 109, 1494-1499. doi: 10.1073/pnas.1115172109

Brennan, D. J., O'Connor, D. P., Rexhepaj, E., Ponten, F., and Gallagher, W. M. (2010). Antibody-based proteomics: fast-tracking molecular diagnostics in oncology. Nat. Rev. Cancer 10, 605-617. doi: 10.1038/ nrc2902

Brinkmann, U., Reiter, Y., Jung, S. H., Lee, B., and Pastan, I. (1993). A recombinant immunotoxin containing a disulfide-stabilized Fv fragment. Proc. Natl. Acad. Sci. U.S.A. 90, 7538-7542. doi: 10.1073/pnas.90.16.7538

Buck, P. M., Kumar, S., Wang, X., Agrawal, N. J., Trout, B. L., and Singh, S. K. (2012). Computational methods to predict therapeutic protein aggregation. Methods Mol. Biol. 899, 425-451. doi: 10.1007/978-1-61779-921-1_26

Bukau, B., and Horwich, A. L. (1998). The Hsp70 and Hsp60 chaperone machines. Cell 92, 351-366. doi: 10.1016/s0092-8674(00) 80928-9

CABLIVI $^{\circledR}$ (2019). Prescribing Information Approved by the U.S. Food and Drug Administration. (U.S. License No. 2085). Ghent: Ablynx NV.

Cai, Y., Zhang, J., Lao, X., Jiang, H., Yu, Y., Deng, Y., et al. (2016). Construction of a disulfide-stabilized diabody against fibroblast growth factor-2 and the inhibition activity in targeting breast cancer. Cancer Sci. 107, 1141-1150. doi: $10.1111 /$ cas.12981

Chao, G., Lau, W. L., Hackel, B. J., Sazinsky, S. L., Lippow, S. M., and Wittrup, K. D. (2006). Isolating and engineering human antibodies using yeast surface display. Nat. Protoc. 1, 755-768. doi: 10.1038/nprot.20 06.94

Chartrain, M., and Chu, L. (2008). Development and production of commercial therapeutic monoclonal antibodies in Mammalian cell expression systems: an 
overview of the current upstream technologies. Curr. Pharm. Biotechnol. 9, 447-467. doi: 10.2174/138920108786786367

Chevalier, A., Silva, D. A., Rocklin, G. J., Hicks, D. R., Vergara, R., Murapa, P., et al. (2017). Massively parallel de novo protein design for targeted therapeutics. Nature 550, 74-79. doi: 10.1038/nature23912

Choi, S. I., Han, K. S., Kim, C. W., Ryu, K. S., Kim, B. H., Kim, K. H., et al. (2008). Protein solubility and folding enhancement by interaction with RNA. PLoS One 3:e2677. doi: 10.1371/journal.pone.0002677

CIMZIA $^{\circledR}$ (2008). Prescribing Information Approved by the U.S. Food and Drug Administration. (US License No. 1736). Smyrna, GE: UCB, Inc.

Conroy, P. J., Hearty, S., Leonard, P., and O'Kennedy, R. J. (2009). Antibody production, design and use for biosensor-based applications. Semin. Cell Dev. Biol. 20, 10-26. doi: 10.1016/j.semcdb.2009.01.010

de la Cruz Edmonds, M. C., Tellers, M., Chan, C., Salmon, P., Robinson, D. K., and Markusen, J. (2006). Development of transfection and high-producer screening protocols for the CHOK1SV cell system. Mol. Biotechnol. 34, 179-190. doi: 10.1385/mb:34:2:179

Demarest, S. J., Chen, G., Kimmel, B. E., Gustafson, D., Wu, J., Salbato, J., et al. (2006). Engineering stability into Escherichia coli secreted Fabs leads to increased functional expression. Protein Eng. Design Select. 19, 325-336. doi: $10.1093 /$ protein/gzl016

Demarest, S. J., and Glaser, S. M. (2008). Antibody therapeutics, antibody engineering, and the merits of protein stability. Curr. Opin. Drug Discov. Dev. $11,675-687$

DePalma, A. (2014). Advances in protein expression. Genet. Eng. Biotechnol. News 34, 24-25. doi: 10.1089/gen.34.01.14

Dudgeon, K., Rouet, R., Kokmeijer, I., Schofield, P., Stolp, J., Langley, D., et al. (2012). General strategy for the generation of human antibody variable domains with increased aggregation resistance. Proc. Natl. Acad. Sci. U.S.A. 109, 1087910884. doi: $10.1073 /$ pnas. 1202866109

Ewert, S., Honegger, A., and Pluckthun, A. (2003). Structure-based improvement of the biophysical properties of immunoglobulin VH domains with a generalizable approach. Biochemistry 42, 1517-1528. doi: 10.1021/bi026448p

Ewert, S., Honegger, A., and Pluckthun, A. (2004). Stability improvement of antibodies for extracellular and intracellular applications: CDR grafting to stable frameworks and structure-based framework engineering. Methods 34, 184-199. doi: 10.1016/j.ymeth.2004.04.007

Famm, K., Hansen, L., Christ, D., and Winter, G. (2008). Thermodynamically stable aggregation-resistant antibody domains through directed evolution. J. Mol. Biol. 376, 926-931. doi: 10.1016/j.jmb.2007.10.075

Feige, M. J., Groscurth, S., Marcinowski, M., Shimizu, Y., Kessler, H., Hendershot, L. M., et al. (2009). An unfolded CH1 domain controls the assembly and secretion of IgG antibodies. Mol. Cell. 34, 569-579. doi: 10.1016/j.molcel.2009. 04.028

Frenzel, A., Hust, M., and Schirrmann, T. (2013). Expression of recombinant antibodies. Front. Immunol. 4:217. doi: 10.3389/fimmu.2013.00217

Gaciarz, A., and Ruddock, L. W. (2017). Complementarity determining regions and frameworks contribute to the disulfide bond independent folding of intrinsically stable scFv. PLoS One 12:e189964. doi: 10.1371/journal.pone. 0189964

Goldenzweig, A., and Fleishman, S. J. (2018). Principles of protein stability and their application in computational design. Annu. Rev. Biochem. 87, 105-129. doi: 10.1146/annurev-biochem-062917-12102

Graff, C. P., Chester, K., Begent, R., and Wittrup, K. D. (2004). Directed evolution of an anti-carcinoembryonic antigen $\mathrm{scFv}$ with a 4-day monovalent dissociation half-time at 37 degrees C. Protein Eng. Design Select. 17, 293-304. doi: 10.1093/ protein/gzh038

Grilo, A. L., and Mantalaris, A. (2019). The increasingly human and profitable monoclonal antibody market. Trends Biotechnol. 37, 9-16. doi: 10.1016/j. tibtech.2018.05.014

Gupta, S. K., and Shukla, P. (2017). Microbial platform technology for recombinant antibody fragment production: a review. Crit. Rev. Microbiol. 43, 31-42. doi: 10.3109/1040841X.2016.1150959

Hartl, F. U., and Hayer-Hartl, M. (2002). Molecular chaperones in the cytosol: from nascent chain to folded protein. Science 295, 1852-1858. doi: 10.1126/science. 1068408

Hendrick, J. P., and Hartl, F. U. (1995). The role of molecular chaperones in protein folding. FASEB J. 9, 1559-1569. doi: 10.1096/fasebj.9.15.8529835
Holliger, P., and Hudson, P. J. (2005). Engineered antibody fragments and the rise of single domains. Nat. Biotechnol. 23, 1126-1136. doi: 10.1038/nbt1142

Holliger, P., Prospero, T., and Winter, G. (1993). "Diabodies": small bivalent and bispecific antibody fragments. Proc. Natl. Acad. Sci. U.S.A. 90, 6444-6448. doi: 10.1073/pnas.90.14.6444

Holms, W. H. (1986). The central metabolic pathways of Escherichia coli: relationship between flux and control at a branch point, efficiency of conversion to biomass, and excretion of acetate. Curr. Top. Cell Regul. 28, 69-105. doi: 10.1016/b978-0-12-152828-7.50004-4

Hsu, H. J., Lee, K. H., Jian, J. W., Chang, H. J., Yu, C. M., Lee, Y. C., et al. (2014). Antibody variable domain interface and framework sequence requirements for stability and function by high-throughput experiments. Structure 22, 22-34. doi: 10.1016/j.str.2013.10.006

Hu, W., Xiang, J. Y., Kong, P., Liu, L., Xie, Q., and Xiang, H. (2017). Expression and characterization of a single-chain variable fragment against human LOX1 in Escherichia coli and Brevibacillus choshinensis. J. Microbiol. Biotechnol. 27, 965-974. doi: 10.4014/jmb.1702.02007

Huang, Y., Li, Y., Wang, Y. G., Gu, X., Wang, Y., and Shen, B. F. (2007). An efficient and targeted gene integration system for high-level antibody expression. J. Immunol. Methods 322, 28-39. doi: 10.1016/j.jim.2007.01.022

Humphreys, D. P. (2003). Production of antibodies and antibody fragments in Escherichia coli and a comparison of their functions, uses and modification. Curr. Opin. Drug Discov. Dev. 6, 188-196.

Ionescu, R. M., Vlasak, J., Price, C., and Kirchmeier, M. (2008). Contribution of variable domains to the stability of humanized IgG1 monoclonal antibodies. J. Pharm. Sci. 97, 1414-1426. doi: 10.1002/jps.21104

Jager, M., and Pluckthun, A. (1999a). Domain interactions in antibody Fv and scFv fragments: effects on unfolding kinetics and equilibria. FEBS Lett. 462, 307-312. doi: 10.1016/s0014-5793(99)01532-x

Jager, M., and Pluckthun, A. (1999b). Folding and assembly of an antibody Fv fragment, a heterodimer stabilized by antigen. J. Mol. Biol. 285, 2005-2019. doi: 10.1006/jmbi.1998.2425

Jefferis, R. (2009). Glycosylation as a strategy to improve antibody-based therapeutics. Nat. Rev. Drug Discov. 8, 226-234. doi: 10.1038/nrd2804

Jespers, L., Schon, O., Famm, K., and Winter, G. (2004). Aggregation-resistant domain antibodies selected on phage by heat denaturation. Nat. Biotechnol. 22, 1161-1165. doi: 10.1038/nbt1000

Jordan, J. L., Arndt, J. W., Hanf, K., Li, G., Hall, J., Demarest, S., et al. (2009). Structural understanding of stabilization patterns in engineered bispecific Iglike antibody molecules. Proteins 77, 832-841. doi: 10.1002/prot.22502

Kang, T. H., and Jung, S. T. (2019). Boosting therapeutic potency of antibodies by taming Fc domain functions. Exp. Mol. Med. 51, 1-9. doi: 10.1038/s12276-0190345-9

Kang, T. H., and Jung, S. T. (2020). Reprogramming the constant region of immunoglobulin $\mathrm{G}$ subclasses for enhanced therapeutic potency against cancer. Biomolecules 10:382. doi: 10.3390/biom10030382

Khodabakhsh, F., Zia, M. F., Moazen, F., Rabbani, M., and Sadeghi, H. M. (2013). Comparison of the cytoplasmic and periplasmic production of reteplase in Escherichia coli. Prep. Biochem. Biotechnol. 43, 613-623. doi: 10.1080/10826068. 2013.764896

Kim, Y. S., Son, A., Kim, J., Kwon, S. B., Kim, M. H., Kim, P., et al. (2018). Chaperna-mediated assembly of ferritin-based middle east respiratory syndrome-coronavirus nanoparticles. Front. Immunol. 9:1093. doi: 10.3389/ fimmu.2018.01093

Kreitman, R. J., and Pastan, I. (2011). Antibody fusion proteins: anti-CD22 recombinant immunotoxin moxetumomab pasudotox. Clin. Cancer Res. 17, 6398-6405. doi: 10.1158/1078-0432.CCR-11-0487

Kunert, R., and Reinhart, D. (2016). Advances in recombinant antibody manufacturing. Appl. Microbiol. Biotechnol. 100, 3451-3461. doi: 10.1007/ s00253-016-7388-9

Kuroda, D., Shirai, H., Jacobson, M. P., and Nakamura, H. (2012). Computer-aided antibody design. Protein Eng. Design Select. 25, 507-521. doi: 10.1093/protein/ gzs024

Lawrence, M. S., Phillips, K. J., and Liu, D. R. (2007). Supercharging proteins can impart unusual resilience. J. Am. Chem. Soc. 129, 10110-10112. doi: 10.1021/ ja071641y

Le Gall, F., Reusch, U., Little, M., and Kipriyanov, S. M. (2004). Effect of linker sequences between the antibody variable domains on the formation, stability 
and biological activity of a bispecific tandem diabody. Protein Eng. Des. Sel. 17, 357-366. doi: 10.1093/protein/gzh039

Lee, J., Der, B. S., Karamitros, C. S., Li, W., Marshall, N. M., Lungu, O. I., et al. (2019). Computer-based engineering of thermostabilized antibody fragments. AIChE J. 66:e16864. doi: 10.1002/aic.16864

Levy, R., Ahluwalia, K., Bohmann, D. J., Giang, H. M., Schwimmer, L. J., Issafras, H., et al. (2013). Enhancement of antibody fragment secretion into the Escherichia coli periplasm by co-expression with the peptidyl prolyl isomerase, FkpA, in the cytoplasm. J. Immunol. Methods 394, 10-21. doi: 10.1016/j.jim. 2013.04.010

Liu, C., Dalby, B., Chen, W., Kilzer, J. M., and Chiou, H. C. (2008). Transient transfection factors for high-level recombinant protein production in suspension cultured mammalian cells. Mol. Biotechnol. 39, 141-153. doi: 10.1007/s12033-008-9051-x

Liu, Z., Zhang, J., Fan, H., Yin, R., Zheng, Z., Xu, Q., et al. (2015). Expression and purification of soluble single-chain Fv against human fibroblast growth factor receptor 3 fused with Sumo tag in Escherichia coli. Electron. J. Biotechnolo. 18, 302-306. doi: 10.1016/j.ejbt.2015.05.006

Lobstein, J., Emrich, C. A., Jeans, C., Faulkner, M., Riggs, P., and Berkmen, M. (2012). SHuffle, a novel Escherichia coli protein expression strain capable of correctly folding disulfide bonded proteins in its cytoplasm. Microb Cell Fact 11:56. doi: 10.1186/1475-2859-11-56

LUCENTIS $^{\circledR}$ (2006). Prescribing Information Approved by the U.S. Food and Drug Administration. South San Francisco, CA: Genentech Inc.

LUMOXITI $^{\mathrm{TM}}$ (2018). PRESCRIBING INFORMATION Approved by the U.S. Food and Drug Administration (U.S. License No. 2059). Wilmington: AstraZeneca Pharmaceuticals LP.

Mack, M., Riethmuller, G., and Kufer, P. (1995). A small bispecific antibody construct expressed as a functional single-chain molecule with high tumor cell cytotoxicity. Proc. Natl. Acad. Sci. U.S.A. 92, 7021-7025. doi: 10.1073/pnas.92. 15.7021

Makino, T., Skretas, G., Kang, T. H., and Georgiou, G. (2011). Comprehensive engineering of Escherichia coli for enhanced expression of IgG antibodies. Metab. Eng. 13, 241-251. doi: 10.1016/j.ymben.2010.11.002

Marcatili, P., Rosi, A., and Tramontano, A. (2008). PIGS: automatic prediction of antibody structures. Bioinformatics 24, 1953-1954. doi: 10.1093/bioinformatics/ btn341

McConnell, A. D., Spasojevich, V., Macomber, J. L., Krapf, I. P., Chen, A., Sheffer, J. C., et al. (2013). An integrated approach to extreme thermostabilization and affinity maturation of an antibody. Protein Eng. Design Select. 26, 151-164. doi: 10.1093/protein/gzs090

McConnell, A. D., Zhang, X., Macomber, J. L., Chau, B., Sheffer, J. C., Rahmanian, S., et al. (2014). A general approach to antibody thermostabilization. $m A b s$, 1274-1282. doi: 10.4161/mabs.29680

McKenna, R., Lombana, T. N., Yamada, M., Mukhyala, K., and Veeravalli, K. (2019). Engineered sigma factors increase full-length antibody expression in Escherichia coli. Metab. Eng. 52, 315-323. doi: 10.1016/j.ymben.2018. 12.009

Miklos, A. E., Kluwe, C., Der, B. S., Pai, S., Sircar, A., Hughes, R. A., et al. (2012). Structure-based design of supercharged, highly thermoresistant antibodies. Chem. Biol. 19, 449-455. doi: 10.1016/j.chembiol.2012.01.018

Miller, B. R., Demarest, S. J., Lugovskoy, A., Huang, F., Wu, X., Snyder, W. B., et al. (2010). Stability engineering of scFvs for the development of bispecific and multivalent antibodies. Protein Eng. Design Select. 23, 549-557. doi: 10.1093/ protein/gzq028

Mizukami, M., Onishi, H., Hanagata, H., Miyauchi, A., Ito, Y., Tokunaga, H., et al. (2018). Efficient production of Trastuzumab Fab antibody fragments in Brevibacillus choshinensis expression system. Protein Expr. Purif. 150, 109-118. doi: $10.1016 /$ j.pep.2018.05.013

Montoliu-Gaya, L., Martinez, J. C., and Villegas, S. (2017). Understanding the contribution of disulfide bridges to the folding and misfolding of an anti-Abeta scFv. Protein Sci. 26, 1138-1149. doi: 10.1002/pro.3164

Nieba, L., Honegger, A., Krebber, C., and Pluckthun, A. (1997). Disrupting the hydrophobic patches at the antibody variable/constant domain interface: improved in vivo folding and physical characterization of an engineered $\mathrm{scFv}$ fragment. Protein Eng. 10, 435-444. doi: 10.1093/protein/10.4.435

Petrus, M. L. C., Kiefer, L. A., Puri, P., Heemskerk, E., Seaman, M. S., Barouch, D. H., et al. (2019). A microbial expression system for high-level production of scFv HIV-neutralizing antibody fragments in Escherichia coli. Appl. Microbiol. Biotechnol. 103, 8875-8888. doi: 10.1007/s00253-019-1014510141

Power, B. E., and Hudson, P. J. (2000). Synthesis of high avidity antibody fragments (scFv multimers) for cancer imaging. J. Immunol. Methods 242, 193-204. doi: 10.1016/s0022-1759(00)00201-5

PRAXBIND $^{\circledR}$ (2015). Prescribing Information Approved by the U.S. Food and Drug Administration. (US License No. 2006). Ingelheim am Rhein: Boehringer Ingelheim Pharmaceuticals Inc.

ReoPro ${ }^{\circledR}$ (1994). Prescribing Information Approved by the U.S. Food and Drug Administration. (U.S. License Number: 1864). Horsham: Janssen Biotech, Inc.

Richards, D. A., Maruani, A., and Chudasama, V. (2017). Antibody fragments as nanoparticle targeting ligands: a step in the right direction. Chem. Sci. 8, 63-77. doi: $10.1039 / \mathrm{c} 6 \mathrm{sc} 02403 \mathrm{c}$

Robinson, M. P., Ke, N., Lobstein, J., Peterson, C., Szkodny, A., Mansell, T. J., et al. (2015). Efficient expression of full-length antibodies in the cytoplasm of engineered bacteria. Nat. Commun. 6:8072. doi: 10.1038/ncomms9072

Rosano, G. L., and Ceccarelli, E. A. (2014). Recombinant protein expression in Escherichia coli: advances and challenges. Front. Microbiol. 5:172. doi: 10.3389/ fmicb.2014.00172

Saerens, D., Huang, L., Bonroy, K., and Muyldermans, S. (2008). Antibody fragments as probe in biosensor development. Sensors 8, 4669-4686. doi: 10. $3390 / \mathrm{s} 8084669$

Saunders, K. O. (2019). Conceptual approaches to modulating antibody effector functions and circulation half-life. Front. Immunol. 10:1296. doi: 10.3389/ fimmu. 2019.01296

Sevy, A. M., Wu, N. C., Gilchuk, I. M., Parrish, E. H., Burger, S., Yousif, D., et al. (2019). Multistate design of influenza antibodies improves affinity and breadth against seasonal viruses. Proc. Natl. Acad. Sci. U.S.A. 116, 1597-1602. doi: $10.1073 /$ pnas. 1806004116

Sircar, A., Kim, E. T., and Gray, J. J. (2009). RosettaAntibody: antibody variable region homology modeling server. Nucleic Acids Res. 37, W474-W479. doi: 10.1093/nar/gkp387

Steipe, B. (2004). Consensus-based engineering of protein stability: from intrabodies to thermostable enzymes. Methods Enzymol. 388, 176-186. doi: 10.1016/S0076-6879(04)88016-9

Strauch, E. M., Bernard, S. M., La, D., Bohn, A. J., Lee, P. S., Anderson, C. E., et al. (2017). Computational design of trimeric influenza-neutralizing proteins targeting the hemagglutinin receptor binding site. Nat. Biotechnol. 35, 667-671. doi: $10.1038 /$ nbt. 3907

Structural Genomics Consortium, China Structural Genomics Consortium, Northeast Structural Genomics, Consortium, Graslund, S., Nordlund, P., Weigelt, J., et al. (2008). Protein production and purification. Nat. Methods 5, 135-146. doi: 10.1038/nmeth.f.202

Suresh, T., Lee, L. X., Joshi, J., and Barta, S. K. (2014). New antibody approaches to lymphoma therapy. J Hematol. Oncol. 7:58. doi: 10.1186/s13045-014-0058-4

Teerinen, T., Valjakka, J., Rouvinen, J., and Takkinen, K. (2006). Structure-based stability engineering of the mouse IgG1 Fab fragment by modifying constant domains. J. Mol. Biol. 361, 687-697. doi: 10.1016/j.jmb.2006.06.073

Terpe, K. (2006). Overview of bacterial expression systems for heterologous protein production: from molecular and biochemical fundamentals to commercial systems. Appl. Microbiol. Biotechnol. 72, 211-222. doi: 10.1007/s00253-006$0465-8$

Tischenko, V. M., Zav'yalov, V. P., Medgyesi, G. A., Potekhin, S. A., and Privalov, P. L. (1982). A thermodynamic study of cooperative structures in rabbit immunoglobulin G. Eur. J. Biochem. 126, 517-521. doi: 10.1111/j.1432-1033. 1982.tb06811.x

Trivedi, M. V., Laurence, J. S., and Siahaan, T. J. (2009). The role of thiols and disulfides on protein stability. Curr. Protein Peptide Sci. 10, 614-625. doi: $10.2174 / 138920309789630534$

Tseng, T. T., Tyler, B. M., and Setubal, J. C. (2009). Protein secretion systems in bacterial-host associations, and their description in the gene ontology. BMC Microbiol. 9(Suppl. 1):S2. doi: 10.1186/1471-2180-9-S1-S2

Vermeer, A. W., and Norde, W. (2000). The thermal stability of immunoglobulin: unfolding and aggregation of a multi-domain protein. Biophys. J. 78, 394-404. doi: 10.1016/S0006-3495(00)76602-1

Wang, R., Xiang, S., Feng, Y., Srinivas, S., Zhang, Y., Lin, M., et al. (2013). Engineering production of functional $\mathrm{scFv}$ antibody in E. coli by co-expressing 
the molecule chaperone Skp. Front. Cell Infect. Microbiol. 3:72. doi: 10.3389/ fcimb.2013.00072

Webber, K. O., Reiter, Y., Brinkmann, U., Kreitman, R., and Pastan, I. (1995). Preparation and characterization of a disulfide-stabilized Fv fragment of the anti-Tac antibody: comparison with its single-chain analog. Mol. Immunol. 32, 249-258. doi: 10.1016/0161-5890(94)00150-y

Whitelegg, N. R. J., and Rees, A. R. (2000). WAM: an improved algorithm for modelling antibodies on the WEB. Protein Eng. 13, 819-824. doi: 10.1093/ protein/13.12.819

Wong, M. S., Wu, S., Causey, T. B., Bennett, G. N., and San, K. Y. (2008). Reduction of acetate accumulation in Escherichia coli cultures for increased recombinant protein production. Metab. Eng. 10, 97-108. doi: 10.1016/j.ymben.2007. 10.003

Wu, J., Fu, J., Zhang, M., and Liu, D. (2015). Blinatumomab: a bispecific T cell engager (BiTE) antibody against CD19/CD3 for refractory acute lymphoid leukemia. J. Hematol. Oncol. 8:104. doi: 10.1186/s13045-015-0195-4

Yamauchi, S., Kobashigawa, Y., Fukuda, N., Teramoto, M., Toyota, Y., Liu, C., et al. (2019). Cyclization of Single-Chain Fv antibodies markedly suppressed their characteristic aggregation mediated by inter-chain VH-VL Interactions. Molecules 24:2620. doi: 10.3390/molecules24142620

Yang, S. W., Jang, Y. H., Kwon, S. B., Lee, Y. J., Chae, W., Byun, Y. H., et al. (2018). Harnessing an RNA-mediated chaperone for the assembly of influenza hemagglutinin in an immunologically relevant conformation. FASEB J. 32, 2658-2675. doi: 10.1096/fj.201700 747RR
Yusakul, G., Nuntawong, P., Sakamoto, S., Ratnatilaka Na Bhuket, P., Kohno, T., Kikkawa, N., et al. (2017). Bacterial expression of a single-chain variable fragment (scFv) Antibody against ganoderic Acid A: a Cost-effective approach for quantitative analysis using the scFv-Based enzyme-linked immunosorbent assay. Biol. Pharm. Bull. 40, 1767-1774. doi: 10.1248/bpb.b1700531

Zhang, K., Geddie, M. L., Kohli, N., Kornaga, T., Kirpotin, D. B., Jiao, Y., et al. (2015). Comprehensive optimization of a single-chain variable domain antibody fragment as a targeting ligand for a cytotoxic nanoparticle. $m A$ s 7 , 42-52. doi: 10.4161/19420862.2014.985933

Zhao, J. X., Yang, L., Gu, Z. N., Chen, H. Q., Tian, F. W., Chen, Y. Q., et al. (2010). Stabilization of the single-chain fragment variable by an interdomain disulfide bond and its effect on antibody affinity. Intern. J. Mol. Sci. 12, 1-11. doi: $10.3390 / \mathrm{ijms} 12010001$

Conflict of Interest: The authors declare that the research was conducted in the absence of any commercial or financial relationships that could be construed as a potential conflict of interest.

Copyright (c) 2020 Kang and Seong. This is an open-access article distributed under the terms of the Creative Commons Attribution License (CC BY). The use, distribution or reproduction in other forums is permitted, provided the original author(s) and the copyright owner(s) are credited and that the original publication in this journal is cited, in accordance with accepted academic practice. No use, distribution or reproduction is permitted which does not comply with these terms. 